\title{
Efficacy of Chronic Antidepressant Treatments in a New Model of Extreme Anxiety in Rats
}

\author{
Hervé Javelot, ${ }^{1,2,3}$ Luisa Weiner, ${ }^{4}$ Roxane Terramorsi, ${ }^{1}$ Catherine Rougeot, ${ }^{5}$ \\ Robert Lalonde, ${ }^{6}$ and Michaël Messaoudi ${ }^{1}$ \\ ${ }^{1}$ Neuropsychopharmacology Department, ETAP-Applied Ethology, 54500 Vandoeuvre-lés-Nancy, France \\ ${ }^{2}$ Service Pharmacie, Etablissement Public de Santé Alsace Nord, 67170 Brumath, France \\ ${ }^{3}$ Laboratoire de Nutrition Génétique et Exposition aux Risques Environnementaux, INSERM U954, \\ Service de Microscopie Electronique, Faculté de Médecine de Nancy, UHP, 54500 Vandoeuvre-les-Nancy, France \\ ${ }^{4}$ Service de Psychiatrie II, CHU de Strasbourg, 67000 Strasbourg, France \\ ${ }^{5}$ Groupe Pharmacologie Moléculaire et Intégrative, Unité de Biochimie Structurale et Cellulaire, Département de Biologie Structurale \\ et Chimie, Institut Pasteur, 75015 Paris, France \\ ${ }^{6}$ CHUM/St-Luc, Neuroscience Research Unit, 1058 St-Denis Street, Montréal, PQ, Canada H2X 3J4
}

Correspondence should be addressed to Hervé Javelot, herve_javelot@yahoo.fr

Received 11 January 2011; Revised 31 May 2011; Accepted 3 June 2011

Academic Editor: Axel Steiger

Copyright (๑) 2011 Hervé Javelot et al. This is an open access article distributed under the Creative Commons Attribution License, which permits unrestricted use, distribution, and reproduction in any medium, provided the original work is properly cited.

\begin{abstract}
Animal models of anxious disorders found in humans, such as panic disorder and posttraumatic stress disorder, usually include spontaneous and conditioned fear that triggers escape and avoidance behaviors. The development of a panic disorder model with a learned component should increase knowledge of mechanisms involved in anxiety disorders. In our ethological model of extreme anxiety in the rat, forced apnea was combined with cold water vaporization in an inescapable situation. Based on the reactions of vehicle controls, behaviors involved in paroxysmic fear were passive (freezing) and active (jumping) reactions. Our results show that subchronic fluoxetine $(5 \mathrm{mg} / \mathrm{kg}, \mathrm{IP}, 21$ days) and imipramine $(10 \mathrm{mg} / \mathrm{kg}, \mathrm{IP}, 14$ days $)$ administration alleviated freezing and jumping behaviors, whereas acute fluoxetine $(1 \mathrm{mg} / \mathrm{kg}$, IP) provoked opposite effects. Acute low dose of diazepam (1 mg/kg, IP) was not effective, whereas the higher dose of $3 \mathrm{mg} / \mathrm{kg}$, IP, and clonazepam $(1 \mathrm{mg} / \mathrm{kg}$, IP) only had an effect on jumping. Paroxysmic fear generated in this experimental condition may therefore mimic the symptomatology observed in patients with anxiety disorders.
\end{abstract}

\section{Introduction}

Rodents' defensive behaviors are often studied in relation to human psychopathology, such as generalized anxiety disorder (GAD), panic disorder (PD), and posttraumatic stress disorder (PTSD). These behaviors consist of immediate defensive reactions connected with the flight or fight system and in anticipatory defensive behaviors, such as risk assessment and neophobic responses [1].

There seems to be a relationship between risk assessment and GAD, on one hand, and escape behaviors and PD on the other [2-4]. Whereas escape behaviors tend to occur in relation to a proximal threat, freezing is connected with distant threats. Both reactions allow a remotely located prey to avoid being detected and to prepare flight or fight responses when confronted with a predator [5-7]. It is noteworthy that wild rodents tend to flee, while laboratorybred rats tend to freeze [8]. Escape is recognized as the most relevant equivalent of panic attacks in the mouse defensive test battery (MDTB) [2], the unstable elevated exposed plusmaze (UEEPM) $[9,10]$, and the elevated T-maze [11]. This behavior is also used in the model of dorsal periaqueductal gray stimulation (dPAG), which appears as a largely valid model for panic [12-17]. Moreover, recent studies using chemical or electrical stimulation, such as inhibition of dorsomedial hypothalamus $[18,19]$ and stimulation of dPAG, suggest that these structures are involved in anxiety disorders [20-25].

Subchronic administration of fluoxetine (FLX), a panicolytic agent in humans, reduced freezing caused by dPAG [26] and contextual fear conditioning [27]. Flight is a crucial response during confrontations with a predator [28] and 
constraining environments, for example, in a natural disaster [1]. When confronted with earthquakes, fires, or floods, panic can be predominant [29-31]. Following Caroline and Robert Blanchard's work on the visible burrow system [28] and the MDTB [32], we propose a constraining environment with a sudden rise of water level akin to flooding of a burrow and underwater trauma-induced stress [33]. Near drowning elicited a more severe response than exposure to a predator's scent [34]. This tangible life-threatening situation may model acute and chronic reactions to stress.

Several data are consistent with our new model. For example, Bouwer and Stein showed an association between $\mathrm{PD}$ and a traumatizing suffocation event [35]. Severson et al. indicate that midbrain 5-hydroxytryptamine (5-HT) neurons are central $\mathrm{pH}$ chemoreceptors [36] and patients with PD have a hypersensitive chemoreceptor system [37] and persistent respiratory difficulties [38]. Moreover, Bouton et al. emphasize the role of conditioning in the development of PD [39].

The present study provides a new ethological model of escape and freezing attempts in rats due to suffocation fear.

The primary aim of our study was to evaluate active (escape attempts) and passive (immobility/freezing) responses to rising water levels and to determine the efficacy of antipanic or anxiolytic agents. FLX is a selective 5HT reuptake inhibitor and imipramine (IMI) a combined noradrenaline and 5-HT reuptake inhibitor both used for treating chronic anxiety disorders, such as PD [40-43] and PTSD [44-47]. Contrary to their panicolytic effects after chronic treatment, 5-HT reuptake blockers sometimes cause a panicogenic effect after acute administration [4850]. Diazepam (DZP) was also tested for its value in treating GAD [51, 52], but to a lesser extent PD and PTSD. Finally, clonazepam (CZP), a high-potency benzodiazepine, is frequently used in the treatment of PD because of its rapid action onset and its good tolerability [53, 54].

\section{Materials and Methods}

2.1. Animals. Naive male Wistar/Han rats, weighing 280 $300 \mathrm{~g}$ at testing onset, were obtained from Harlan (The Netherlands). Prior to testing, the rats were housed in a regulated environment (humidity $50 \pm 5 \%$; temperature $22 \pm$ $2^{\circ} \mathrm{C}$; lights on 20:00-08:00). They were allowed free access to food (food pellets 2016, Teklad, USA) and tap water ad libitum. After an acclimatization period of 7 days, the rats were weighed and randomly distributed in treatment groups. The present protocol respects the guidelines provided by the ASAB Ethical Committee for the treatment of animals in behavioral research and teaching (Animal Behavior 2006, 71, 245-253), by the Canadian Council on Animal Care (Guide to the Care and Use of Experimental Animals: Vol. 1, 2nd Edn., 1993, vol. 2, 1984), and by the European Communities Council Directive of 24 November 1986 (86/609/EEC).

2.2. Drugs. FLX, IMI, DZP, and CZP were purchased from Sigma, France. All drugs were administered in a volume of $1 \mathrm{~mL} / \mathrm{kg}$ body weight. Separate groups of animals were used in the evaluation of aversive behaviors. The effects of FLX $(5 \mathrm{mg} / \mathrm{kg}, \mathrm{IP})$ and IMI $(10 \mathrm{mg} / \mathrm{kg}$, IP) were assessed after subchronic administration of 21 and 14 days, respectively. On test day, FLX and IMI were administered $30 \mathrm{~min}$ before testing. DZP (1 and $3 \mathrm{mg} / \mathrm{kg}, \mathrm{IP}), \mathrm{CZP}(1 \mathrm{mg} / \mathrm{kg}$, IP), and FLX $(10 \mathrm{mg} / \mathrm{kg}$, IP) were assessed after acute administration 30 min before testing. Doses were chosen on the basis of previous results in anxiety or panic models: for DZP $[26,55]$, CZP [3], FLX [18, 55], and IMI [56, 57]. FLX and IMI were dissolved in a $0.9 \%$ saline solution, DZP and CZP in a $40 \%$ propylene glycol-10\% ethanol vehicle. The control groups were given a $0.9 \%$ saline solution for experiments with FLX and IMI and a $40 \%$ propylene glycol- $10 \%$ ethanol solution for DZP and CZP.

2.3. Apparatus. The apparatus consisted of a transparent Plexiglas cylinder (diameter $20 \mathrm{~cm}$, height $60 \mathrm{~cm}$ ) placed on a glass plate. Above the cylinder protruded a shower pommel connected to a tap for water delivery at $15^{\circ} \mathrm{C}$. In the "Intermittent cold water swim stress" paradigm, Christianson and Drugan [58] used this temperature and their pilot studies indicated that $15^{\circ} \mathrm{C}$ was the lowest temperature that did not harm the rats' health. In the "Stress by immersion in cold water" Retana-Márquez et al. model [59], rats were placed in a tank of water at the same temperature.

Two types of cylinders were employed. In habituation and test sessions, the cylinder contained a hole, allowing water drainage and the possibility of jumping (height of water level $10 \mathrm{~cm}$ ). In conditioning sessions (see below), water was accumulated as the hole was closed up.

2.4. Procedure. The paradigm comprised 6-test sessions of 6 min: two habituation sessions (morning and afternoon of day 1), two conditioning sessions (morning and afternoon of day 2), and two test sessions (baseline before treatments and test after treatment administration) (Figure 1). The baseline session took place in the morning of day 3 , and the test session was held either in the morning of day 4 for acute assessment or a few days later, also in the morning, for subchronic assessment.

In the habituation session, the rat was placed inside the dry cylinder and water was delivered during a 2 to $5 \mathrm{~min}$ period on the glass plate beside the cylinder. The rat was left for an additional min and then returned to its home cage (Figure 1(a)).

In the conditioning session, the rat was placed inside the dry cylinder again for $1 \mathrm{~min}$. During the following $3 \mathrm{~min}$, water was jet propulsed on the glass plate. From the fourth min on, water was vaporized on the rat for $90 \mathrm{~s}$. Water delivery was then stopped and the rat underwent a $30 \mathrm{~s}$ period of partial apnea by closing the top of the cylinder with a perforated lid. The time spent underwater was based on the "underwater procedure" described in Richter-Levin's underwater trauma model [33], in which rats swim for $1 \mathrm{~min}$ in a water maze [60] without an escape platform and then are forcibly held under water for $30 \mathrm{~s}$ by a metal net. In our model, at the end of the partial apnea phase, the rat was dried off with paper towels and then returned to 


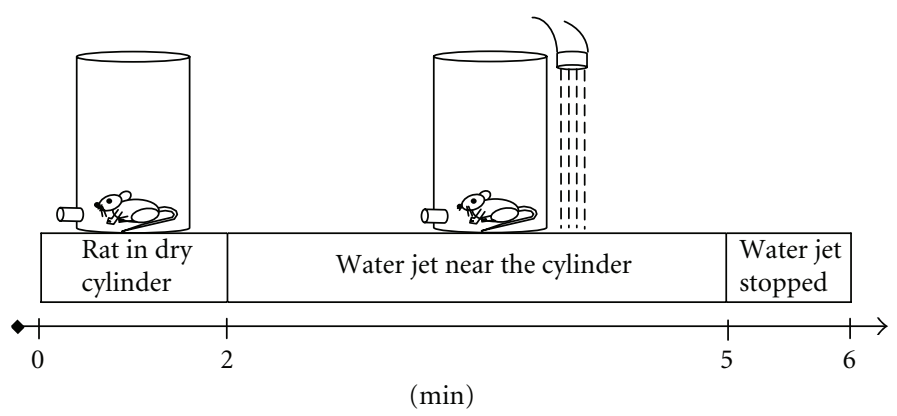

(a) Habituation session in perforated cylinder

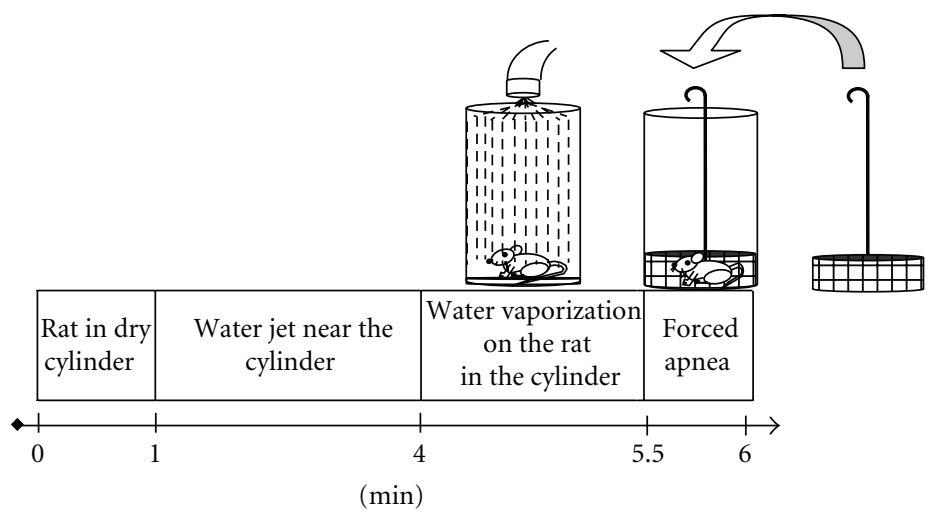

(b) Conditioning session in nonperforated cylinder



(c) Test session in perforated cylinder

FIGURE 1: Schematic representation of the procedure used for assessment of behavioral responses. (a) Habituation session in perforated cylinder. (b) Conditioning session in nonperforated cylinder. (c) Test session in perforated cylinder.

its home cage (Figure 1(b)). In the test session, the same procedure was repeated, except that no forced apnea was applied (Figure 1(c)).

Rat behaviors were video recorded during test sessions and scored by experimenters unaware of treatment variables. The number and latencies of jumps were measured, together with freezing time, defined by immobility for at least $4 \mathrm{~s}$ in the interval of 0 to $4 \mathrm{~min}$.

2.5. Statistical Analyses. The Mann-Whitney $U$ test was used in order to compare group effects. For repeated measures, the Wilcoxon test was used. Data are expressed as the median with limits of interquartile range values, and the level of significance is fixed at $P<0.05$. The statistical analyses were carried out with Statview 5.0 software (SAS Institute, Carey, USA, 1992-1998).

\section{Results}

3.1. Subchronic Fluoxetine ( $5 \mathrm{mg} / \mathrm{kg}, I P, 21$ days). As shown in Table 1, jumping prior to injections was not different between the groups ( $U=39.50$; NS) but FLX administration decreased jumping compared with vehicle $(U=15.50$; $P=$ $0.03)$. While jumping frequency during baseline and test sessions was stable in controls $(z=0.77$; NS) it decreased in FLX-treated rats $(z=2.37 ; P=0.02)$. Likewise, immobility time between the two groups did not differ at baseline $(U=24$; NS), but was altered after drug administration 
TABLE 1: Effects of subchronic fluoxetine (FLX) treatment ( $5 \mathrm{mg} / \mathrm{kg} / 21 \mathrm{~d}, \mathrm{IP}, n=9$, median with limits of interquartile range values). MannWhitney $U$ test: ${ }^{*} P<0.05$; ${ }^{* *} P<0.01$ (FLX versus Vehicle). Wilcoxon-test: ${ }^{\#} P<0.05$ (test versus baseline). Data were expressed as median with limits of interquartile range values.

\begin{tabular}{lcccc}
\hline \multirow{2}{*}{ Measures } & \multicolumn{2}{c}{ Baseline (before treatment) } & \multicolumn{2}{c}{ Test (after treatment) } \\
& Vehicle $(n=9)$ & FLX $(n=9)$ & Vehicle $(n=9)$ & FLX $(n=9)$ \\
\hline Number of jumps & $23(9.8-37.3)$ & $21(16.5-31.5)$ & $22(10.5-27)$ & $9^{* \#}(0-12.8)$ \\
Latency before the first jump (s) & $15(11.3-21.5)$ & $14(11.8-23.3)$ & $16(12.3-18)$ & $27^{* \#}(16.3-90)$ \\
Immobility (s) & $140(126.8-144.8)$ & $59(33.3-93.8)$ & $164^{\#}(140-176.8)$ & $70^{* *}(58.8-115)$ \\
\hline
\end{tabular}

TABLE 2: Effects of subchronic imipramine (IMI) treatment $(10 \mathrm{mg} / \mathrm{kg} / 14 \mathrm{~d}, \mathrm{IP}, n=7$, median with limits of interquartile range values). Mann-Whitney $U$ test: ${ }^{*} P<0.05$; ${ }^{* *} P<0.01$ (IMI versus vehicle). Wilcoxon-test: ${ }^{\#} P<0.05$ (test versus baseline). Data were expressed as median with limits of interquartile range values.

\begin{tabular}{lcccc}
\hline \multirow{2}{*}{ Measures } & \multicolumn{2}{c}{ Baseline (before treatment) } & \multicolumn{2}{c}{ Test (after treatment) } \\
& Vehicle $(n=7)$ & IMI $(n=7)$ & Vehicle $(n=7)$ & IMI $(n=7)$ \\
\hline Number of jumps & $24(17.3-29)$ & $22(15.8-25)$ & $28(24.5-32.5)$ & $15^{* * *}(1.8-18.8)$ \\
Latency before the first jump (s) & $5(3.3-11)$ & $12(6.3-24.3)$ & $10(7.3-18)$ & $22^{* * \#}(19.8-74.5)$ \\
Immobility (s) & $107(93.5-117)$ & $103(93.5-150.8)$ & $157^{\#}(124.8-182.5)$ & $86^{*}(33.5-128.5)$ \\
\hline
\end{tabular}

$(U=7 ; P=0.003)$. The duration of immobility in baseline and test sessions remained stable in FLX-treated rats $(z=$ 0.65 ; NS), but increased in controls $(z=2.55 ; P=0.01)$.

3.2. Subchronic Imipramine (10 mg/kg, IP, 14 days). As seen in Table 2, the groups did not differ in terms of jumps prior to injections ( $U=21.50$; NS). After injections, IMI-treated rats displayed fewer jumps $(U=3 ; P=0.006)$. The number of jumps between baseline and testing was unchanged in control rats $(z=0.85$; NS), while it decreased in IMI-treated rats $(z=2.03 ; P=0.04)$. IMI-treated rats showed lower immobility time after injections $(U=6 ; P=0.02)$, but not at baseline ( $U=23$; NS). Relative to baseline, immobility time did not decrease significantly in IMI-treated rats $(z=1.69$; $P=0.09)$ while it increased in controls $(z=2.37 ; P=0.02)$.

3.3. Acute Diazepam ( $1 \mathrm{mg} / \mathrm{kg}$, IP). As seen in Table 3, jumping frequencies did not differ before or after injections ( $U=34.50$; NS on baseline and $U=25$; NS on test) and remained stable in both groups $(z=0.42$; NS for controls and $z=1.72$; NS for DZP-treated rats). No significant difference was observed in the duration of immobility between the two groups during baseline and test session ( $U=37.5$; NS on baseline and $U=21$; NS, on test). The duration of immobility remained stable in DZP-treated rats between the two test sessions ( $z=1.24$; NS), while it increased in control rats $(z=2.07 ; P=0.04)$.

3.4. Acute Diazepam ( $3 \mathrm{mg} / \mathrm{kg}$, IP). As seen in Table 4, duration of immobility, number of jumps, and jumping latencies were not different between vehicle and DZP groups before treatment ( $U=45,39.5$ and 46.5; NS, resp.). During the test session, DZP-treated rats showed fewer jumps $(U=$ 19.5; $P=0.02$ ), the latency before the first jump was higher in this group $(U=19.5 ; P=0.02)$, and immobility was similar in both groups ( $U=43.5$; NS). This last parameter increased significantly between baseline and test session in the vehicle and DZP-treated rats $(z=2.70 ; P=0.007$ and $z=2.80 ; P=0.005$, resp.). The number of jumps remained stable in control rats $(z=0.05$; NS) but decreased in DZPtreated ones $(z=2.70 ; P=0.007)$. Jumping frequencies remained stable in the two groups $(z=1.58$; NS for controls and $z=1.32$; NS for DZP-treated rats).

3.5. Acute Clonazepam ( $1 \mathrm{mg} / \mathrm{kg}, \mathrm{IP})$. As seen in Table 5, duration of immobility, number of jumps, and jumping latencies were not different between vehicle and CZP groups at baseline ( $U=39.5,36.5$ and 31.5 ; NS, resp.). During test session, CZP-treated rats displayed fewer jumps ( $U=0$; $P=0.0003$ ), the latency before the first jump was higher in this group $(U=13 ; P=0.01)$, and immobility was similar in both groups $(U=39$; NS). The immobility duration increased significantly between baseline and test session in both groups $(z=2.55 ; P=0.01$ for controls and $z=1.95 ; P=0.05$ for CZP-treated rats). The number of jumps remained stable in control rats $(z=0.41$; NS), while it decreased in CZP-treated rats $(z=2.67 ; P=0.008)$. Jumping frequency remained stable in controls $(z=0.21$; NS), whereas it increased in CZP-treated rats $(z=2.55$; $P=0.01)$.

3.6. Acute Fluoxetine $(1 \mathrm{mg} / \mathrm{kg}, \mathrm{IP})$. As seen in Table 6 , the results from acute FLX rats differed from those of chronic FLX animals. Jumping frequencies did not differ before or after injections (baseline: $U=34.50$; NS and test: $U=38$; NS). While jumping frequency remained stable in controls $(z=1.72$; NS), it increased in FLX-treated rats $(z=2.31$; $P=0.02$ ). The duration of immobility was not different between the two groups during baseline and test sessions (baseline: $U=27$; NS and test: $U=20$; NS). However, this 
TABle 3: Effects of acute diazepam (DZP) treatment ( $1 \mathrm{mg} / \mathrm{kg}$, IP, $n=9$, median with limits of interquartile range values). Wilcoxon-test: ${ }^{\#} P<0.05$ (test versus baseline). Data were expressed as median with limits of interquartile range values.

\begin{tabular}{lcccc}
\hline \multirow{2}{*}{ Measures } & \multicolumn{2}{c}{ Baseline (before treatment) } & \multicolumn{2}{c}{ Test (after treatment) } \\
& Vehicle $(n=9)$ & DZP $(n=9)$ & Vehicle $(n=9)$ & DZP $(n=9)$ \\
\hline Number of jumps & $20(15.5-23.5)$ & $21(15.3-28.8)$ & $21(17.5-23.3)$ & $16(12.3-22.3)$ \\
Latency before the first jump (s) & $17(9.8-21.8)$ & $15(10.8-20.8)$ & $13(9.8-15.5)$ & $21(14.0-23.3)$ \\
Immobility (s) & $106(61.5-125.5)$ & $101(80.3-129.8)$ & $121^{\#}(104.0-141.3)$ & $90(75.0-103.0)$ \\
\hline
\end{tabular}

TABLE 4: Effects of acute diazepam (DZP) treatment ( $3 \mathrm{mg} / \mathrm{kg}$, IP, $n=9$, median with limits of interquartile range values). Mann-Whitney $U$ test: ${ }^{*} P<0.05$ (DZP versus vehicle). Wilcoxon-test: ${ }^{\#} P<0.01$ (test versus baseline). Data were expressed as median with limits of interquartile range values.

\begin{tabular}{|c|c|c|c|c|}
\hline \multirow{2}{*}{ Measures } & \multicolumn{2}{|c|}{ Baseline (before treatment) } & \multicolumn{2}{|c|}{ Test (after treatment) } \\
\hline & Vehicle $(n=9)$ & $\mathrm{DZP}(n=9)$ & Vehicle $(n=9)$ & $\operatorname{DZP}(n=9)$ \\
\hline Number of jumps & $13.5(12-17)$ & $15.5(8-28)$ & $15(10-19)$ & $6^{* \# \#(4-14)}$ \\
\hline Latency before the first jump (s) & $15.5(12-25)$ & $23.5(6-34)$ & $11(6-20)$ & $28^{*}(12-78)$ \\
\hline Immobility (s) & $84(44-129)$ & $85.5(52-120)$ & $129.5^{\# \#}(90-176)$ & $130^{\# \#(83-171)}$ \\
\hline
\end{tabular}

variable increased in FLX-treated rats and controls $(z=2.31$; $P=0.02$ and $z=1.96 ; P=0.05$, resp.).

\section{Discussion}

Panic disorder is characterized not only by the presence of unexpected and recurring panic attacks, but also by a persistent and intense fear of further attacks. According to Klein [61], Barlow's psychological model of panic attacks [62] suggests that they are related to an oversensitiveness to $\mathrm{CO}_{2}[63,64]$ which was later confirmed in clinical-setting studies [65]. This oversensitiveness could be explained by a disturbed warning system involved in suffocation fear. The false alarm leads to acute dyspnea, fear of impending death, and an urgent need to flee. Models of panic using pharmacological agents, such as sodium lactate, $5 \% \mathrm{CO}_{2}$, or doxapram (respiratory analeptic), induce false suffocation alarms, similar to those found in panic attack in terms of physiological specificity and pharmacological reactivity $[38,61,66-70]$, and doxapram has been also used in the rodent to determine its neuroanatomic basis [71].

The behaviors observed during panic attacks (flight, acute dyspnea) and the experimental conditions that we have developed in the forced apnea test define the face validity of our model. The combination of $30 \mathrm{~s}$ forced apnea and cold water appears necessary in our model to induce a chronic stress reaction with significant behavioral expression related to paroxystic fear (unpublished data).

4.1. Task Parameters. Two stressors were used cold water and restraint/immobilisation-in order to model extreme fear conditions. Cold stress is a well-documented stressor in rats [72-74]. For example, Jedema and Grace [75] demonstrated activation of locus coeruleus neurons after exposure to low temperatures in rats, thus central noradrenergic function seems potentially modifiable in anxiety. Hyperventilation and tachycardia occur before cold water immersion in humans as a form of anticipatory anxiety [76], and the "cold shock" itself causes an "inspiratory gasp," hyperventilation and secondary dyspnea, hypocapnia, tachycardia, and hypertension [77]. These somatic symptoms are akin to spontaneous manifestations during panic attacks [61].

The main purpose of our study was to create ethological fear sequences through flooding inside a rodent's burrow. Combined restraint and cold stressors are relevant in inducing chronic stress conditions in rats [78, 79]. Restraint/immobilisation combined with cold water immersion produces more behavioral alterations than immobilisation alone [80]. Likewise, Retana-Márquez et al. [59] showed stressful effects induced by immersion in cold water, both acutely and chronically.

The number of jumps, the latency before the first jump, and the immobility time were assessed in male adult rats exposed to our model. In placebo controls, paroxysmic fear induced both active (jumps) and passive (immobility) reactions. At baseline, all rats jumped every $3.5 \mathrm{~s}$ during vaporisation, indicating that this is a typical reaction to a proximal threat. The same animals spent $87.5 \%$ of their time in a freezing posture during application of water beside the cylinder, suggesting that this models a typical reaction to a distant threat. Richter-Levin [33] used water trauma in a model of PTSD. Similarly, classical conditioning is probably involved in PD [39]; Bouwer and Stein [35] showed a relationship between PD and near drowning. Taken together, these data support the idea that severe anxiety disorders and panic attacks may be mimicked in laboratory settings and still be ethically acceptable because of their brief duration.

4.2. Subchronic Fluoxetine and Imipramine. Subchronic administration of FLX and IMI caused similar effects. Both substances decreased jumps and immobility time and increased time latency before the first jump. All these three effects are attributable to their anxiopanicolytic properties. They concur with those of PD paradigms. With the MDTB, Griebel et al. [56] reported a significant decrease in 
TABLE 5: Effects of acute clonazepam (CZP) treatment ( $1 \mathrm{mg} / \mathrm{kg}$, IP, $n=9$, median with limits of interquartile range values). Mann-Whitney $U$ test: ${ }^{*} P<0.05 ;{ }^{* *} P<0.01$ (CZP versus vehicle). Wilcoxon-test: ${ }^{\#} P \leq 0.05$; ${ }^{\# \#} P<0.01$ (test versus baseline). Data were expressed as median with limits of interquartile range values.

\begin{tabular}{lcccc}
\hline \multirow{2}{*}{ Measures } & \multicolumn{2}{c}{ Baseline (before treatment) } & \multicolumn{2}{c}{ Test (after treatment) } \\
& Vehicle $(n=9)$ & CZP $(n=9)$ & Vehicle $(n=9)$ & CZP $(n=9)$ \\
\hline Number of jumps & $17(9.75-21.75)$ & $15(11-17)$ & $18(15.25-20.5)$ & $33^{* * \# \#}(2-8)$ \\
Latency before the first jump (s) & $14(6.5-35.75)$ & $12(4.5-19.5)$ & $10(7.25-31)$ & $68^{* \#}(20.5-75)$ \\
Immobility (s) & $90(50-133.5)$ & $85(65.25-115)$ & $130^{\#}(92-162)$ & $125^{\#}(104-145.5)$ \\
\hline
\end{tabular}

TABLE 6: Effects of acute fluoxetine (FLX) treatment ( $10 \mathrm{mg} / \mathrm{kg}$, IP, $n=9$, median with limits of interquartile range values). Wilcoxon-test: ${ }^{\#} P<0.05$ (test versus baseline). Data are expressed as median with limits of interquartile range values.

\begin{tabular}{lcccc}
\hline \multirow{2}{*}{ Measures } & \multicolumn{2}{c}{ Baseline (before treatment) } & \multicolumn{2}{c}{ Test (after treatment) } \\
& Vehicle $(n=9)$ & FLX $(n=9)$ & Vehicle $(n=9)$ & $19(16.8-24.8)$ \\
\hline $\begin{array}{l}\text { Number of jumps } \\
\text { Latency before the first }\end{array}$ & $17(13.5-19.5)$ & $15(13.3-17.8)$ & $16(13.0-17.8)$ & $21^{\#}(19.0-22.5)$ \\
jump (s) & $19(12.8-27.3)$ & $20(14.8-29.5)$ & $14^{\#}(4.8-19.5)$ \\
Immobility (s) & $85(68.0-98.0)$ & $97(81.5-114.8)$ & $108^{\#}(93.8-126.3)$ & $139^{\#}(115.0-159.3)$ \\
\hline
\end{tabular}

the number of mouse escapes from a predator (anaesthetised rat) after FLX treatment for 21 days at the dose of $5 \mathrm{mg} / \mathrm{kg}$ IP. Likewise, in the UEEPM [9], the number of escapes of FLXtreated rats $(10 \mathrm{mg} / \mathrm{kg}, \mathrm{PO})$ was lower than that of controls. Moreover, Vargas and Schenberg [81] showed that 3-week FLX treatment at the dose of $5 \mathrm{mg} / \mathrm{kg}$, IP, increased dPAG stimulation thresholds causing escape attempts. Similarly, various selective serotonin reuptake inhibitor (SSRIs), such as citalopram, FLX, paroxetine, sertraline, and escitalopram, reduced the flight-like escape behavior produced by dPAG electrical stimulation in the rat $[12,13]$. Borelli et al. [26] found that 2-week FLX treatment at $5 \mathrm{mg} / \mathrm{kg}$, IP, increased dPAG stimulation thresholds for freezing, but not escape attempts. The latter data, as our own, indicate that freezing is a relevant measure in animal models of extreme anxiety, although the main characteristics of panic is the flight response. These results suggest that FLX decreases freezing responses in rats under intense fear conditions. They are also consistent with the results obtained by Santos et al. [27]. Moreover, the CCK-4 (cholecystokinin type 2 (CCK(2)) receptor agonist) intradorsolateral periaqueductal gray injection facilitated the expression of both freezing and escape behaviors [14]. These data support the hypothesis that both locomotor reactions are closely related to panic behaviors and should be taken into account given their high expression levels in our model.

At the pharmacological level, chronic administration of SSRIs treatments appears to sensitize 5-HT1A receptors in the dPAG and supports the idea that facilitation of 5HT1A receptor-mediated neurotransmission in the dPAG is implicated in the pharmacotherapy of $\mathrm{PD}[13,16,17]$.

Finally, FLX, paroxetine, and sertraline SSRIs are also effective in different models of PTSD in rats [82-84].
Tricyclic agents, such as IMI at $10 \mathrm{mg} / \mathrm{kg} / 14 \mathrm{~d}$, had similar effects to those obtained with FLX at $5 \mathrm{mg} / \mathrm{kg} / 21 \mathrm{~d}$ in terms of escape attempts and freezing duration. In the MDTB "predator avoidance test," IMI at 5 and $10 \mathrm{mg} / \mathrm{kg}$ for 21 days decreased mouse avoidance distance and frequency of escapes from the rat [56]. Likewise, Jacob et al. [85] showed that a 3-week IMI treatment at $15 \mathrm{mg} / \mathrm{kg}$, IP, produced an enhancement of the antiaversive effect of 5-HT receptor agonists locally injected into the PAG. Blanchard et al. [86] observed a decrease of freezing in rats after presentation of a cat after 3-week IMI treatment at $15 \mathrm{mg} / \mathrm{kg}$, IP. Our results are reminiscent of successful PD and PTSD treatments [4047] after chronic administration of IMI or FLX in clinical studies.

4.3. Acute Benzodiazepines. DZP is not considered to be as effective as other antipanic agents [87]. At $1 \mathrm{mg} / \mathrm{kg}$, DZP only prevents the increase of immobility after fear conditioning and has no effect on escape attempts. Likewise, no effect was observed after PAG stimulation with DZP at the doses of 1,2 , and $4 \mathrm{mg} / \mathrm{kg}$, IP [26] and one-way escape was not affected by DZP at $0.5,1,2$, and $4 \mathrm{mg} / \mathrm{kg}$, IP in the elevated T-maze [11]. However, Griebel et al. [55] found a panicolytic effect with DZP at $3 \mathrm{mg} / \mathrm{kg}$ in the MDTB but not at 0.5 and $1 \mathrm{mg} / \mathrm{kg}$, IP. In our model, DZP, at $3 \mathrm{mg} / \mathrm{kg}$, IP, decreases the number of jumps, without affecting the duration of immobility as it was previously noted with a lower dose. Our interpretation of these results is that, at $1 \mathrm{mg} / \mathrm{kg}$, IP, DZP only acts on anticipatory anxiety (freezing), without interacting with panic reaction (jumps), whereas, at $3 \mathrm{mg} / \mathrm{kg}$, IP, its sedative effects mask its potential effect on anxiety, but is able to decrease panic-related symptoms. Li et al. [88] evaluated the effects of DZP in a PTSD model—consisting of 
a 2-day foot shock $(0.8 \mathrm{~mA}, 10 \mathrm{~s})$ period followed by 3 weekly situational reminders. After 26-day IP administration, DZP at a low dose of $0.25 \mathrm{mg} / \mathrm{kg}$, but not at $4 \mathrm{mg} / \mathrm{kg}$, reduced behavioral deficiencies. Additional data is therefore needed concerning possible benzodiazepine effects at variable doses, such as subchronic administration and a wider range of doses used in our paradigm. Although benzodiazepines are used in the short-term treatment of PTSD, long-term treatment with these molecules is not effective [89-91].

In addition, a 3-day treatment with CZP at $5 \mathrm{mg} / \mathrm{kg}$, IP, completely blocked the effects of bicuculline following its infusion in dorsomedial hypothalamus [19]. After acute CZP administration at $0.1,0.56$, and $1 \mathrm{mg} / \mathrm{kg}$, IP, Jenck [92] noted that it reduced, in a dose-related manner, aversive behaviors induced by dPAG stimulation. In the MDTB, CZP single doses of 0.3 and $1 \mathrm{mg} / \mathrm{kg}$, IP, decreased avoidance distance and avoidance reactions [3]. In our study, CZP only affected the number of jumps. Unlike our results following DZP administration, a significant increase of latency before the first jump was observed between baseline and test after CZP intake. This effect can be explained by CZP's superior efficacy on panic attack symptoms compared to DZP. Conversely, CZP did not prevent the increase of immobility after forced apnea. These results are consistent with the clinical data suggesting that CZP reduces panic attack intensity but has no effect on anticipatory anxiety in PD [93].

At the pharmacological level, alprazolam facilitates 5HT1A receptor-mediated neurotransmission in the dPAG, like SSRIs [15]. This could partially explain the similar effects obtained by SSRIs, high-potency benzodiazepines, such as alprazolam and clonazepam, and low-potency benzodiazepine, such as diazepam at sedating doses, on flight-like escape behaviors.

4.4. Acute Fluoxetine. The panicogenic effect of acute FLX is a well-known parameter in clinical practice [49] or in animal experimentation [3]. In the MDTB, acute FLX increased avoidance distance [56]. However, in the UEEPM, acute FLX did not increase rodent escape behavior [9], and in dPAG stimulation models, acute FLX either attenuated escape behaviors [94] or had no effect on these behaviours [26]. In our model, FLX at $10 \mathrm{mg} / \mathrm{kg}$, IP, had a panicogenic effect which was measured via the comparison of two ethological variables between baseline and test session in FLX-treated rats, that is, increase of the number of jumps and decrease of latency before the first jump.

In conclusion, our model is an innovative behavioral paradigm that may improve investigation of anxiety disorder. Our results are consistent with the hypothesis that effective drugs for GAD and PD/PTSD have differential effects on specific defensive behaviors in rats. Antidepressant agents, such as IMI and FLX, counteract anticipatory anxiety and panic symptoms, whereas high potency benzodiazepines or low potency benzodiazepines at sedating doses only affect the panic-related symptoms.

Clinical observations also seem to converge with our results. Indeed, benzodiazepines immediately decrease panic attack-related anxiety symptoms; however, antidepressant drugs remain the gold standard treatment for the long-term management of PD [95].

\section{Acknowledgment}

The authors want to express their gratitude to the Professor Catherine Strazielle for revising the text.

\section{References}

[1] R. Misslin, "The defense system of fear: behavior and neurocircuitry," Neurophysiologie Clinique, vol. 33, no. 2, pp. 55-66, 2003.

[2] D. C. Blanchard, G. Griebel, and R. J. Blanchard, "Mouse defensive behaviors: pharmacological and behavioral assays for anxiety and panic," Neuroscience and Biobehavioral Reviews, vol. 25, no. 3, pp. 205-218, 2001.

[3] D. C. Blanchard, G. Griebel, and R. J. Blanchard, "The Mouse Defense Test Battery: pharmacological and behavioral assays for anxiety and panic," European Journal of Pharmacology, vol. 463, no. 1-3, pp. 97-116, 2003.

[4] R. L. Pobbe, H. Zangrossi, D. C. Blanchard, and R. J. Blanchard, "Involvement of dorsal raphe nucleus and dorsal periaqueductal gray 5-HT receptors in the modulation of mouse defensive behaviors," European Neuropsychopharmacology, vol. 21, no. 4, pp. 306-315, 2010.

[5] R. J. Blanchard and D. C. Blanchard, "Passive and active reactions to fear-eliciting stimuli," Journal of Comparative and Physiological Psychology, vol. 68, no. 1, pp. 129-135, 1969.

[6] R. J. Blanchard, D. C. Blanchard, T. Takahashi, and M. J. Kelley, "Attack and defensive behaviour in the albino rat," Animal Behaviour, vol. 25, no. 3, pp. 622-634, 1977.

[7] M.S. Fanselow, "Neural organization of the defensive behavior system responsible for fear," Psychonomic Bulletin \& Review, vol. 1, pp. 429-438, 1994.

[8] R. J. Blanchard, K. J. Flannelly, and D. C. Blanchard, "Defensive behavior of laboratory and wild Rattus norvegicus," Journal of Comparative Psychology, vol. 100, no. 2, pp. 101$107,1986$.

[9] N. Jones, S. M. King, and M. S. Duxon, "Further evidence for the predictive validity of the unstable elevated exposed plusmaze, a behavioural model of extreme anxiety in rats: differential effects of fluoxetine and chlordiazepoxide," Behavioural Pharmacology, vol. 13, no. 7, pp. 525-535, 2002.

[10] N. Jones, M. S. Duxon, and S. M. King, "Ethopharmacological analysis of the unstable elevated exposed plus maze, a novel model of extreme anxiety: predictive validity and sensitivity to anxiogenic agents," Psychopharmacology, vol. 161, no. 3, pp. 314-323, 2002.

[11] F. G. Graeff, C. Ferreira Netto, and H. Zangrossi, "The elevated T-maze as an experimental model of anxiety," Neuroscience and Biobehavioral Reviews, vol. 23, no. 2, pp. 237-246, 1998.

[12] S. Hogg, L. Michan, and M. Jessa, "Prediction of anti-panic properties of escitalopram in the dorsal periaqueductal grey model of panic anxiety," Neuropharmacology, vol. 51, no. 1, pp. 141-145, 2006.

[13] J. M. Zanoveli, R. L. Nogueira, and H. Zangrossi, "Enhanced reactivity of 5-HT1A receptors in the rat dorsal periaqueductal gray matter after chronic treatment with fluoxetine and sertraline: evidence from the elevated T-maze," Neuropharmacology, vol. 52, no. 4, pp. 1188-1195, 2007.

[14] L. J. Bertoglio, V. C. de Bortoli, and H. Zangrossi, "Cholecystokinin-2 receptors modulate freezing and escape 
behaviors evoked by the electrical stimulation of the rat dorsolateral periaqueductal gray," Brain Research, vol. 1156, no. 1, pp. 133-138, 2007.

[15] V. C. De Bortoli, R. L. Nogueira, and H. Zangrossi, "Alprazolam potentiates the antiaversive effect induced by the activation of 5-HT1A and 5-HT2A receptors in the rat dorsal periaqueductal gray," Psychopharmacology, vol. 198, no. 3, pp. 341-349, 2008.

[16] J. M. Zanoveli, R. L. H. Pobbe, V. C. De Bortoli, M. C. Carvalho, M. L. Brando, and H. Zangrossi, "Facilitation of 5HT1A-mediated neurotransmission in dorsal periaqueductal grey matter accounts for the panicolytic-like effect of chronic fluoxetine," International Journal of Neuropsychopharmacology, vol. 13, no. 8, pp. 1079-1088, 2010.

[17] J. M. Zanoveli, R. L. Nogueira, and H. Zangrossi, "Serotonin in the dorsal periaqueductal gray modulates inhibitory avoidance and one-way escape behaviors in the elevated T-maze," European Journal of Pharmacology, vol. 473, no. 2-3, pp. 153$161,2003$.

[18] A. Shekhar and J. A. DiMicco, "Defense reaction elicited by injection of GABA antagonists and synthesis inhibitors into the posterior hypothalamus in rats," Neuropharmacology, vol. 26, no. 5, pp. 407-417, 1987.

[19] A. Shekhar, "Effects of treatment with imipramine and clonazepam on an animal model of panic disorder," Biological Psychiatry, vol. 36, no. 11, pp. 748-758, 1994.

[20] F. G. Graeff and C. M. Del-Ben, "Neurobiology of panic disorder: from animal models to brain neuroimaging," Neuroscience and Biobehavioral Reviews, vol. 32, no. 7, pp. 1326-1335, 2008.

[21] P. L. Johnson, W. Truitt, S. D. Fitz et al., "A key role for orexin in panic anxiety," Nature Medicine, vol. 16, no. 1, pp. 111-115, 2010.

[22] P. S. D. M. Yamashita, V. C. De Bortoli, and H. Zangrossi, "5HT2C receptor regulation of defensive responses in the rat dorsal periaqueductal gray," Neuropharmacology, vol. 60, no. 2-3, pp. 216-222, 2011.

[23] R. L. H. Pobbe, H. Zangrossi, D. C. Blanchard, and R. J. Blanchard, "Involvement of dorsal raphe nucleus and dorsal periaqueductal gray 5-HT receptors in the modulation of mouse defensive behaviors," European Neuropsychopharmacology, 2010.

[24] T. L. B. Miguel, R. L. H. Pobbe, A. Spiacci, and H. Zangrossi, "Dorsal raphe nucleus regulation of a panic-like defensive behavior evoked by chemical stimulation of the rat dorsal periaqueductal gray matter," Behavioural Brain Research, vol. 213, no. 2, pp. 195-200, 2010.

[25] P. C. Casarotto, V. C. De Bortoli, F. M. De Aguiar Corra, L. B. Moraes Resstel, and H. Zangrossi, "Panicolytic-like effect of BDNF in the rat dorsal periaqueductal grey matter: the role of 5-HT and GABA," International Journal of Neuropsychopharmacology, vol. 13, no. 5, pp. 573-582, 2010.

[26] K. G. Borelli, M. J. Nobre, M. L. Brandao et al., "Effects of acute and chronic fluoxetine and diazepam on freezing behavior induced by electrical stimulation of dorsolateral and lateral columns of the periaqueductal gray matter," Behavioural Brain Research, vol. 77, no. 3, pp. 557-566, 2004.

[27] J. M. Santos, R. C. R. Martinez, and M. L. Brandão, "Effects of acute and subchronic treatments with fluoxetine and desipramine on the memory of fear in moderate and high-intensity contextual conditioning," European Journal of Pharmacology, vol. 542, no. 1-3, pp. 121-128, 2006.

[28] R. J. Blanchard and D. C. Blanchard, "Antipredator defensive behaviors in a visible burrow system," Journal of Comparative Psychology, vol. 103, no. 1, pp. 70-82, 1989.
[29] D. Helbing, I. Farkas, and T. Vicsek, "Simulating dynamical features of escape panic," Nature, vol. 407, no. 6803, pp. 487490, 2000.

[30] J. Kang, D.K. Wright, S. F. Qin, and Y. Zhao, "Modeling human behaviors and reactions under dangerous environment," Biomedical Sciences Instrumentation, vol. 42, pp. 265-270, 2005.

[31] C. Saloma, G. J. Perez, G. Tapang, M. Lim, and C. PalmesSaloma, "Self-organized queuing and scale-free behavior in real escape panic," Proceedings of the National Academy of Sciences of the United States of America, vol. 100, no. 21, pp. 11947-11952, 2003.

[32] D. C. Blanchard, K. Hori, R. J. Rodgers, C. A. Hendrie, and R. J. Blanchard, "Attenuation of defensive threat and attack in wild rats (Rattus rattus) by benzodiazepines," Psychopharmacology, vol. 97, no. 3, pp. 392-401, 1989.

[33] G. Richter-Levin, "Acute and long-term behavioral correlates ofunderwater trauma- potential relevance to stress and poststress syndromes," Psychiatry Research, vol. 79, no. 1, pp. 7383, 1998

[34] H. Cohen, J. Zohar, M. A. Matar, K. Zeev, U. Loewenthal, and G. Richter-Levin, "Setting apart the affected: the use of behavioral criteria in animal models of post traumatic stress disorder," Neuropsychopharmacology, vol. 29, no. 11, pp. 19621970, 2004.

[35] C. Bouwer and D. J. Stein, "Association of panic disorder with a history of traumatic suffocation," American Journal of Psychiatry, vol. 154, no. 11, pp. 1566-1570, 1997.

[36] C. A. Severson, W. Wang, V. A. Pieribone, C. I. Dohle, and G. B. Richerson, "Midbrain serotonergic neurons are central pH chemoreceptors," Nature Neuroscience, vol. 6, no. 11, pp. 1139-1140, 2003.

[37] J. M. Gorman, M. R. Liebowitz, A. J. Fyer, and J. Stein, "A neuroanatomical hypothesis for panic disorder," American Journal of Psychiatry, vol. 146, no. 2, pp. 148-161, 1989.

[38] J. L. Abelson, J. G. Weg, R. M. Nesse, and G. C. Curtis, "Persistent respiratory irregularity in patients with panic disorder," Biological Psychiatry, vol. 49, no. 7, pp. 588-595, 2001.

[39] M. E. Bouton, S. Mineka, and D. H. Barlow, "A modern learning theory perspective on the etiology of panic disorder," Psychological Review, vol. 108, no. 1, pp. 4-32, 2001.

[40] A. Bakker, A. J. L. M. Van Balkom, and R. Van Dyck, "Selective serotonin reuptake inhibitors in the treatment of panic disorder and agoraphobia," International Clinical Psychopharmacology, vol. 15, no. 2, pp. S25-S30, 2000.

[41] H. Garakani, C. M. Zitrin, and D. F. Klein, "Treatment of panic disorder with imipramine alone," American Journal of Psychiatry, vol. 141, no. 3, pp. 446-448, 1984.

[42] S. Kasper and E. Resinger, "Panic disorder: the place of benzodiazepines and selective serotonin reuptake inhibitors," European Neuropsychopharmacology, vol. 11, no. 4, pp. 307321, 2001.

[43] C. M. Zitrin, D. F. Klein, M. G. Woerner, and D. C. Ross, "Treatment of phobias. I. Comparison of imipramine hydrochloride and placebo," Archives of General Psychiatry, vol. 40, no. 2, pp. 125-138, 1983.

[44] K. M. Connor, S. M. Sutherland, L. A. Tupler, M. L. Malik, and J. R. T. Davidson, "Fluoxetine in post-traumatic stress disorder. Randomised, double-blind study," British Journal of Psychiatry, vol. 175, pp. 17-22, 1999.

[45] S. Falcon, C. Ryan, K. Chamberlain, and G. Curtis, "Tricyclics: possible treatment for posttraumatic stress disorder," Journal of Clinical Psychiatry, vol. 46, no. 9, pp. 385-388, 1985. 
[46] J. B. Frank, T. R. Kosten, E. L. Giller, and E. Dan, "A randomized clinical trial of phenelzine and imipramine for posttraumatic stress disorder," American Journal of Psychiatry, vol. 145, no. 10, pp. 1289-1291, 1988.

[47] F. Martenyi, E. B. Brown, H. Zhang, A. Prakash, and S. C. Koke, "Fluoxetine versus placebo in posttraumatic stress disorder," Journal of Clinical Psychiatry, vol. 63, no. 3, pp. 199 206, 2002.

[48] A. Saran and A. Halaris, "Panic attack precipitated by fluoxetine," The Journal of Neuropsychiatry and Clinical Neurosciences, vol. 1, no. 2, pp. 219-220, 1989.

[49] J. A. den Boer and H. G. Westenberg, "Serotonin function in panic disorder: a double blind placebo controlled study with fluvoxamine and ritanserin," Psychopharmacology, vol. 102, no. 1, pp. 85-94, 1990.

[50] G. Catalano, S. M. Hakala, and M. C. Catalano, "Sertralineinduced panic attacks," Clinical Neuropharmacology, vol. 23, no. 3, pp. 164-168, 2000.

[51] R. Fontaine, G. Chouinard, and L. Annable, "Bromazepam and diazepam in generalized anxiety: a placebo-controlled study of efficacy and withdrawal," Psychopharmacology Bulletin, vol. 20, no. 1, pp. 126-127, 1984.

[52] T. Pourmotabbed, D. R. Mcleod, R. Hoehn-Saric, P. Hipsley, and D. J. Greenblatt, "Treatment, discontinuation, and psychomotor effects of diazepam in women with generalized anxiety disorder," Journal of Clinical Psychopharmacology, vol. 16, no. 3, pp. 202-207, 1996.

[53] A. E. Nardi, R. C. Freire, A. M. Valença et al., "Tapering clonazepam in patients with panic disorder after at least 3 years of treatment," Journal of Clinical Psychopharmacology, vol. 30, no. 3, pp. 290-293, 2010.

[54] A. E. Nardi, R. C. Freire, A. M. Valença et al., "Randomized, open naturalistic, acute treatment of panic disorder with clonazepam or paroxetine," Journal of Clinical Psychopharmacology, vol. 31, no. 2, pp. 259-261, 2011.

[55] G. Griebel, G. Perrault, and D. J. Sanger, "Characterization of the behavioral profile of the non peptide CRF receptor antagonist GP-154,526 in anxiety models in rodents. Comparison with diazepam and buspirone," Psychopharmacology, vol. 138, no. 1, pp. 55-66, 1998.

[56] G. Griebel, D. C. Blanchard, R. S. Agnes, and R. J. Blanchard, "Differential modulation of antipredator defensive behavior in Swiss-Webster mice following acute or chronic administration of imipramine and fluoxetine," Psychopharmacology, vol. 120, no. 1, pp. 57-66, 1995.

[57] R. C. Teixeira, H. Zangrossi, and F. Graeff, "Behavioral effects of acute and chronic imipramine in the elevated T-maze model of anxiety," Pharmacology Biochemistry and Behavior, vol. 65, no. 4, pp. 571-576, 2000.

[58] J. P. Christianson and R. C. Drugan, "Intermittent cold water swim stress increases immobility and interferes with escape performance in rat," Behavioural Brain Research, vol. 165, no. 1, pp. 58-62, 2005.

[59] S. Retana-Márquez, H. Bonilla-Jaime, G. Vázquez-Palacios, R. Martínez-García, and J. Velázquez-Moctezuma, "Changes in masculine sexual behavior, corticosterone and testosterone in response to acute and chronic stress in male rats," Hormones and Behavior, vol. 44, no. 4, pp. 327-337, 2003.

[60] R. Morris, "Developments of a water-maze procedure for studying spatial learning in the rat," Journal of Neuroscience Methods, vol. 11, no. 1, pp. 47-60, 1984.
[61] D. F. Klein, "False suffocation alarms, spontaneous panics, and related conditions: an integrative hypothesis," Archives of General Psychiatry, vol. 50, no. 4, pp. 306-317, 1993.

[62] D. H. Barlow, Anxiety and its Disorders. The Nature and Treatment of Anxiety and Panic, Guilford Press, New York, NY, USA, 1988.

[63] M. R. Fyer, J. Uy, J. Martinez et al., "CO2 challenge of patients with panic disorder," American Journal of Psychiatry, vol. 144, no. 8, pp. 1080-1082, 1987.

[64] E. J. L. Griez, H. Lousberg, M. A. Van den Hout, and G. M. Van der Molen, "CO2 vulnerability in panic disorder," Psychiatry Research, vol. 20, no. 2, pp. 87-95, 1987.

[65] J. M. Gorman, L. A. Papp, J. D. Coplan et al., "Anxiogenic effects of $\mathrm{CO} 2$ and hyperventilation in patients with panic disorder," American Journal of Psychiatry, vol. 151, no. 4, pp. 547-553, 1994.

[66] T. W. Uhde, "Caffeine: practical facts for the psychiatrist," in Anxiety: New Research Findings for the Clinician, P. P. RoyByrne, Ed., pp. 73-88, American Psychiatric Press, Washington, DC, USA, 1988.

[67] J. M. Gorman, R. R. Goetz, D. Dillon et al., "Sodium D-lactate infusion of panic disorder patients," Neuropsychopharmacology, vol. 3, no. 3, pp. 181-190, 1990.

[68] J. L. Abelson, R. M. Nesse, J. G. Weg, and G. C. Curtis, "Respiratory psychophysiology and anxiety: cognitive intervention in the doxapram model of panic," Psychosomatic Medicine, vol. 58, no. 4, pp. 302-313, 1996.

[69] D. A. Gutman, J. Coplan, L. Papp, J. Martinez, and J. Gorman, "Doxapram-induced panic attacks and cortisol elevation," Psychiatry Research, vol. 133, no. 2-3, pp. 253-261, 2005.

[70] J. M. Kent, J. D. Coplan, O. Mawlawi et al., "Prediction of panic response to a respiratory stimulant by reduced orbitofrontal cerebral blood flow in panic disorder," American Journal of Psychiatry, vol. 162, no. 7, pp. 1379-1381, 2005.

[71] G. M. Sullivan, J. Apergis, J. M. Gorman, and J. E. LeDoux, "Rodent doxapram model of panic: behavioral effects and cFos immunoreactivity in the amygdala," Biological Psychiatry, vol. 53, no. 10, pp. 863-870, 2003.

[72] G. A. Metz, N. M. Jadavji, and L. K. Smith, "Modulation of motor function by stress: a novel concept of the effects of stress and corticosterone on behavior," European Journal of Neuroscience, vol. 22, no. 5, pp. 1190-1200, 2005.

[73] M. C. Pardon, S. Ma, and D. A. Morilak, "Chronic cold stress sensitizes brain noradrenergic reactivity and noradrenergic facilitation of the HPA stress response in Wistar Kyoto rats," Brain Research, vol. 971, no. 1, pp. 55-65, 2003.

[74] T. Tazumi, E. Hori, T. Uwano et al., "Effects of prenatal maternal stress by repeated cold environment on behavioral and emotional development in the rat offspring," Behavioural Brain Research, vol. 162, no. 1, pp. 153-160, 2005.

[75] H. P. Jedema and A. A. Grace, "Chronic exposure to cold stress alters electrophysiological properties of locus coeruleus neurons recorded in vitro," Neuropsychopharmacology, vol. 28, no. 1, pp. 63-72, 2003.

[76] W. M. Suess, A. B. Alexander, and D. D. Smith, "The effects of psychological stress on respiration: a preliminary study of anxiety and hyperventilation," Psychophysiology, vol. 17, no. 6, pp. 535-540, 1980.

[77] A. Datta and M. Tipton, "Respiratory responses to cold water immersion: neural pathways, interactions, and clinical consequences awake and asleep," Journal of Applied Physiology, vol. 100, no. 6, pp. 2057-2064, 2006. 
[78] V. Klenerová, O. Kaminský, P. Šída, I. Krejčí, Z. Hliák, and S. Hynie, "Impaired passive avoidance acquisition in Sprague-Dawley and Lewis rats after restraint and cold stress," Behavioural Brain Research, vol. 136, no. 1, pp. 21-29, 2002.

[79] V. Klenerová, J. Jurčovičová, O. Kaminský et al., "Combined restraint and cold stress in rats: effects on memory processing in passive avoidance task and on plasma levels of ACTH and corticosterone," Behavioural Brain Research, vol. 142, no. 1-2, pp. 143-149, 2003.

[80] V. Klenerová, P. Sida, I. Krejci et al., "Effects of two types of restraint stress on spontaneous behavior of Sprague-Dawley and Lewis rats," Journal of Physiology and Pharmacology, vol. 58, no. 1, pp. 83-94, 2007.

[81] L. C. Vargas and L. C. Schenberg, "Long-term effects of clomipramine and fluoxetine on dorsal periaqueductal greyevoked innate defensive behaviours of the rat," Psychopharmacology, vol. 155, no. 3, pp. 260-268, 2001.

[82] B. H. Harvey, C. Naciti, L. Brand, and D. J. Stein, "Serotonin and stress: protective or malevolent actions in the biobehavioral response to repeated trauma?" Annals of the New York Academy of Sciences, vol. 1032, pp. 267-272, 2004.

[83] M. A. Matar, H. Cohen, Z. Kaplan, and J. Zohar, "The effect of early poststressor intervention with sertraline on behavioral responses in an animal model of post-traumatic stress disorder," Neuropsychopharmacology, vol. 31, no. 12, pp. 2610 2618, 2006.

[84] T. Takahashi, S. Morinobu, Y. Iwamoto, and S. Yamawaki, "Effect of paroxetine on enhanced contextual fear induced by single prolonged stress in rats," Psychopharmacology, vol. 189, no. 2, pp. 165-173, 2006.

[85] C. A. Jacob, A. H. Caabral, L. P. Almeida et al., "Chronic imipramine enhances 5-HT(1A) and 5- $\mathrm{HT}(2)$ receptorsmediated inhibition of panic-like behavior in the rat dorsal periaqueductal gray," Pharmacology Biochemistry and Behavior, vol. 72, no. 4, pp. 761-766, 2002.

[86] R. J. Blanchard, J. K. Shepherd, R. J. Rodgers, L. Magee, and D. C. Blanchard, "Attenuation of antipredator defensive behavior in rats following chronic treatment with imipramine," Psychopharmacology, vol. 110, no. 1-2, pp. 245-253, 1993.

[87] D. J. Nutt, “The pharmacology of human anxiety," Pharmacology and Therapeutics, vol. 47, no. 2, pp. 233-266, 1990.

[88] S. Li, Y. Murakami, M. Wang et al., "The effects of chronic valproate and diazepam in a mouse model of posttraumatic stress disorder," Pharmacology Biochemistry and Behavior, vol. 85, no. 2, pp. 324-331, 2006.

[89] M. E. Cates, M. H. Bishop, L. L. Davis, J. S. Lowe, and T. W. Woolley, "Clonazepam for treatment of sleep disturbances associated with combat-related posttraumatic stress disorder," Annals of Pharmacotherapy, vol. 38, no. 9, pp. 1395-1399, 2004.

[90] E. Gelpin, O. Bonne, T. Peri, D. Brandes, and A. Y. Shalev, "Treatment of recent trauma survivors with benzodiazepines: a prospective study," Journal of Clinical Psychiatry, vol. 57, no. 9, pp. 390-394, 1996.

[91] R. K. Pitman and D. L. Delahanty, "Conceptually driven pharmacologic approaches to acute trauma," CNS Spectrums, vol. 10, no. 2, pp. 99-106, 2005.

[92] F. Jenck, "Dorsal periaqueductal gray-induced aversion as a simulation of panic anxiety: elements of face and predictive validity," Psychiatry Research, vol. 57, no. 2, pp. 181-191, 1995.

[93] G. E. Tesar, J. F. Rosenbaum, M. H. Pollack et al., "Doubleblind, placebo-controlled comparison of clonazepam and alprazolam for panic disorder," Journal of Clinical Psychiatry, vol. 52, no. 2, pp. 69-76, 1991.

[94] L. C. Schenberg, L. B. Capucho, R. O. Vatanabe, and L. C. Vargas, "Acute effects of clomipramine and fluoxetine on dorsal periaqueductal grey-evoked unconditioned defensive behaviours of the rat," Psychopharmacology, vol. 159, no. 2, pp. 138-144, 2002.

[95] M. Bourin and O. Lambert, "Pharmacotherapy of anxious disorders," Human Psychopharmacology, vol. 17, no. 8, pp. 383400, 2002. 


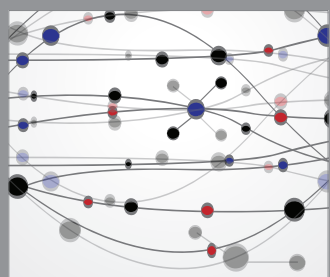

The Scientific World Journal
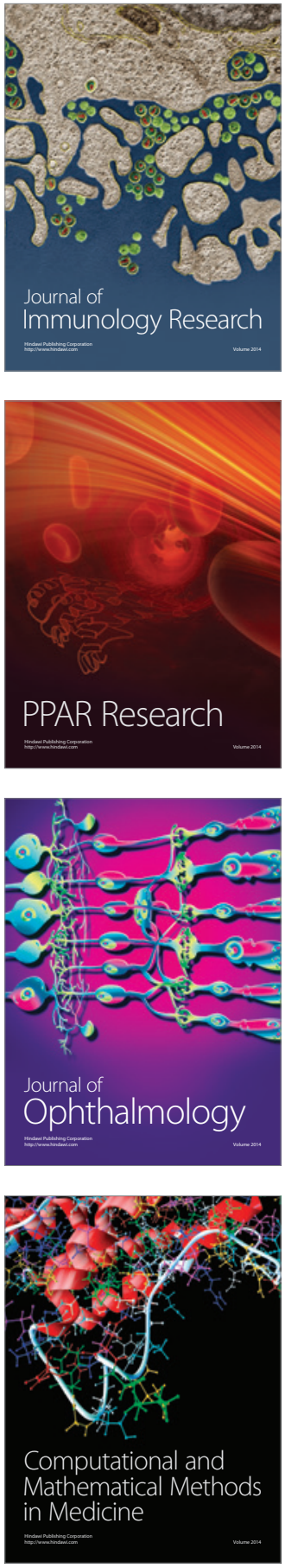

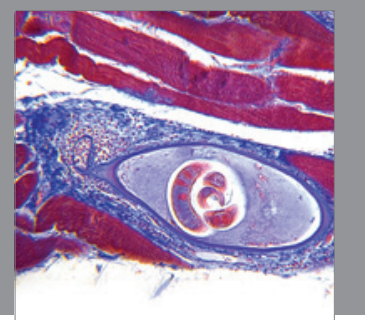

Gastroenterology

Research and Practice
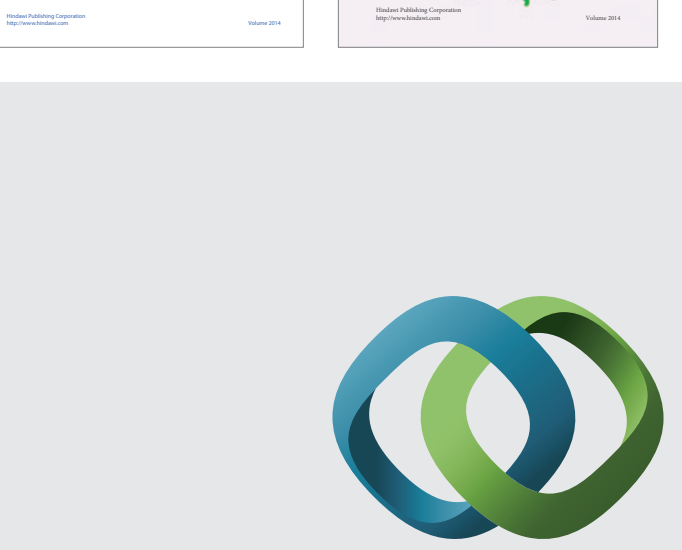

\section{Hindawi}

Submit your manuscripts at

http://www.hindawi.com
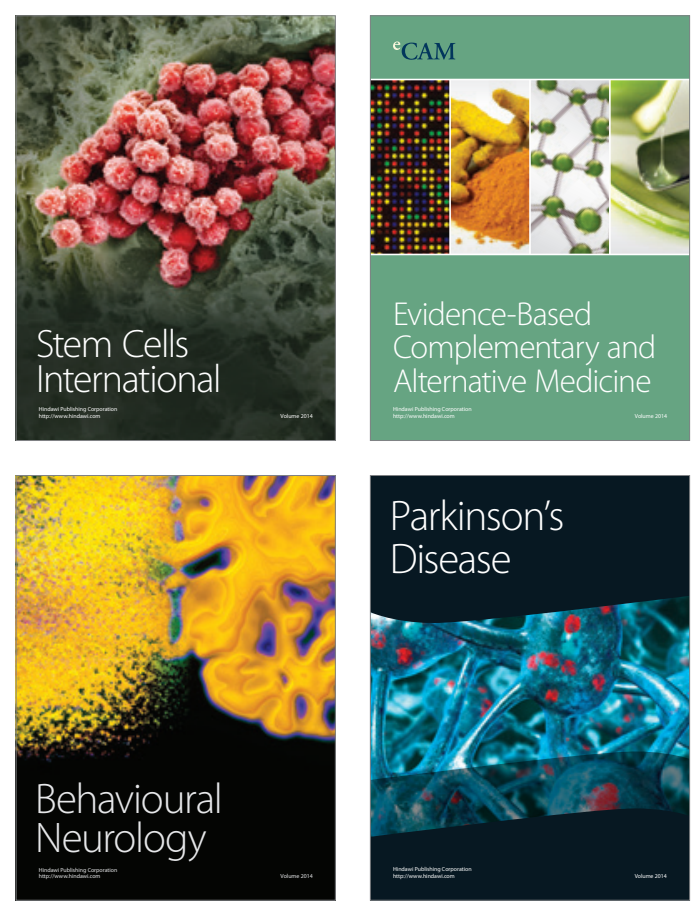

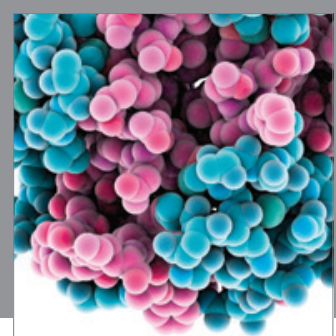

Journal of
Diabetes Research

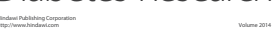

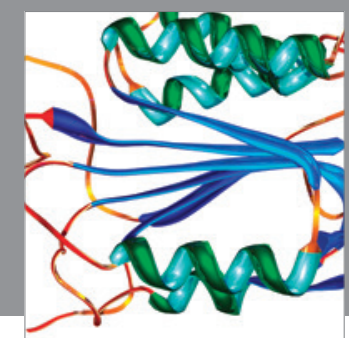

Disease Markers
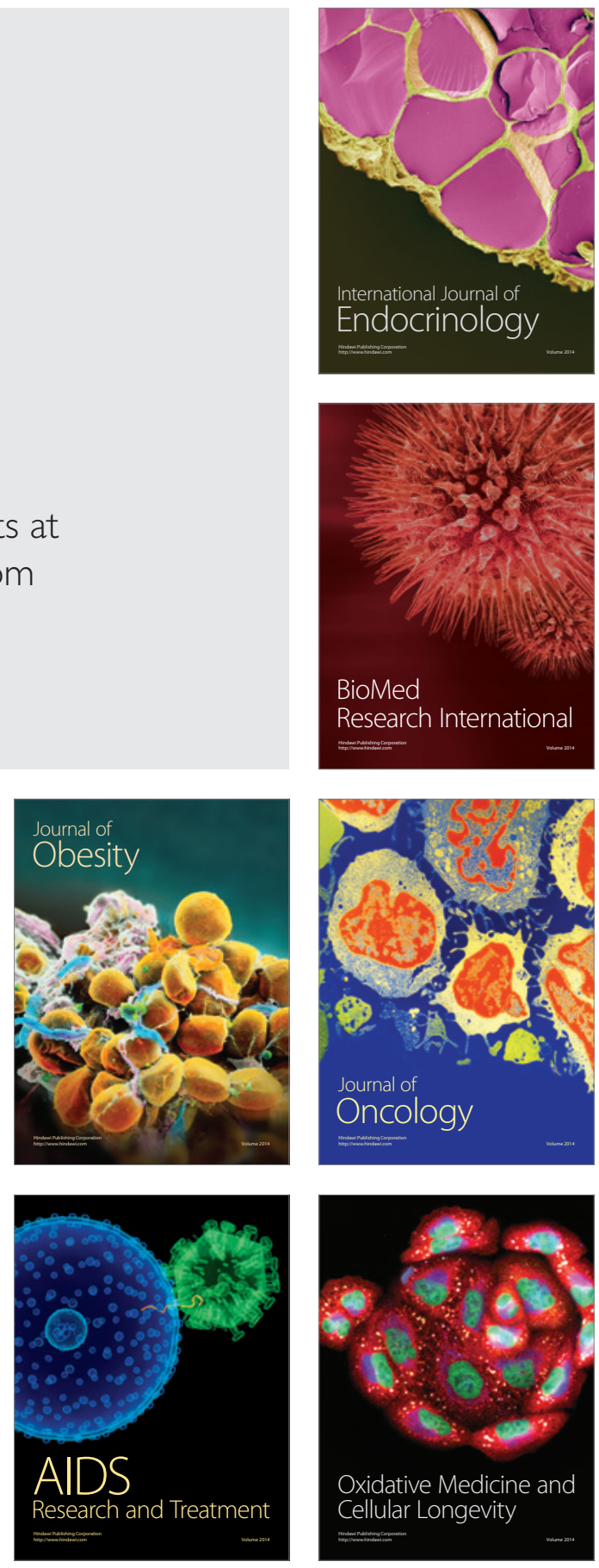